Journal of Architectural
Research and Development

Research in Context
BIQ-BYWORD

By Du Ting

\title{
The Investigation on the Status Quo of the Traditional Folk Houses and Former Residences in Binzhou and the Research on Experience Tourism Development
}

--Taking Du Shoutian's Former Residence as an Example

(Binzhou University, Binzhou City 256600, Shandong, China)

\section{Introduction}

Binzhou city in China is seated in the north of Shandong Province and located in the hinterland of the Yellow River Delta. More than 8,000 years ago, the Dongyi people and their culture were breeded here. Since the Houli culture, the development of the regional history of Binzhou has never been interrupted and abundant historical relics have been preserved.[1] With the mention of the traditional folk houses in Binzhou, the readers may hear of the Manor of the Wei Family. It is an architectural miracle springing up in the North Shandong Plain. Binzhou owns the largest and most completely preserved castlestyle folk house which dates back to the Qing Dynasty and is found currently. Besides, it also owns dozens of traditional folk houses of the former residence category. The investigation, research and protection work involving these buildings is a task of great urgency $^{[2]}$.

\section{Investigation on the Status Quo of Typical Cases}

Du Shoutian's former residence fully reflects the humanistic color of a Qing Dynasty homestead. The former residence of Du Shoutian, established during the Wanli years of the Ming Dynasty, has a simple architectural style and is a typical northern Shandong building of the
Published online: $30^{\text {th }}$ Nov., 2017

Corresponding author: Du Ting, Email:451515753@qq.com.

Ming and Qing Dynasties. It covers an area of about 20 acres and has more than 187 houses ${ }^{[3]}$.

\subsection{Spatial Layout}

The characteristics of the overall layout is openness without any closed place. Taking the aisle behind the screen wall of the main entrance, the whole courtyard can be divided into two parts: the northern part and the southern part. The entrance doors and aisles are set in all directions: the east, the west, the south and the north, which makes it possible to reach any directions. The back door and the side door are set up in each courtyard, connected by a gateway or corridor. They are independent but accessible to each other, which can make people imagine the intimacy of this family.

\subsection{Decoration Characteristics}

"As spotlessly clean as a lotus flower, experience affairs of human life and also can rise above the world. The void is like the moon in

\begin{abstract}
With the convening of the Ancient Village Assembly, Binzhou city in China has attached more and more importance to the protection and development of ancient villages and folk houses. Compared with a complete village, the folk houses are distributed dispersedly, which puts forward more requirements to the tourism development of the former residence. Taking Du Shoutian's former residence as an example and based on the analysis of its architectural features and status quo, this paper puts forward the tourism development strategy of the activation and utilization of the former residence buildings in accordance with the experience economy theory. The main ways are as follows: enhancing the entertainment, aesthetic, escape and education experience. To provide the effective basis to the future development of former residence buildings.
\end{abstract}

Key words: Traditional folk houses; Du Shoutian's former residence; Experience economy; Tourism development 
the water while the Buddhist allegory is the arcanum of the words." [4] After entering the former residence, the visitor can notice the tablets hung right above the entrance door. The tablets include "Mansion of Fangbo", "Mansion of Premier", etc. A tablet of "The grandfather, grandson, father, son, uncle and nephew of this family are members of the Imperial Academy" is hung inside the second door. The story of six Imperial Academy members in four generations of a family has become a much-told tale in Binzhou and has turned into an anecdote that everyone knows. The visitors can see these tablets only by entering the door, which reflects the humility and low profile of the Du Family. These tablets are not only the merits and honors of the Du Family but also the achievements made by the Du Family's descendants who persevered in their studies in spite of hardships and had gone through the mill.

On the screen wall, there is a lotus pattern representing the first-class official. The lotus symbolizes honesty and uprightness. Hundreds of the Du family members were government officials and many of them were local leaders, commanders of borderprovinces and important cabinet ministers. Some were demoted because of being upright and outspoken, some were dismissed from office because of being a dissident and some died with a martyr's death. However, they all had a common trait: incorruptibility. As government officials, they were willing to work for the people. Even acting as government officials for one term, they had brought benefits to the local people and left a lot of much-told stories ${ }^{[5]}$.

\subsection{Architectural Structure}

The former residence is a frame architecture with four beams and eight pillars. The historic buildings in China are wood-made frame structures. The beam-column should be the first to be erected and then the wall should be built. Its technological process is similar to that of the buildings of modern frame structure. The material collocation of the wall is stressed and the wall is built by piling up mixed sundried mud and black bricks. Among them, in terms of the gable wall as well as the back wall of the house, the black bricks should be wrapped up with sundried mud to increase the thickness of the wall, which can bring the effects of heat preservation and heat insulation. In winter, the wall can withstand extreme cold. But in summer, the thick wall can also play a part in heat protection $^{[6]}$

The reason why the Du Family courtyard is world-famous is that it has become the epitome of an era and has been solidified into a cultural symbol with rich meanings. In this cultural symbol, the buildings with the richest cultural deposits are the principal room and the boudoir.

Imperial Academy Hall is the reception room of the Du Family, where the Du Family can receive their important guests. Built in the middle of the Ming Dynasty, it has three rooms and five beams and is often called by later generations as "Imperial Academy Hall" as well as "Prime Minister Hall". This is the principal room, built in the Wanli years of the Ming Dynasty, it is a singlestorey house of the brick-wood structure with three wide rooms, two deep rooms, four beams and eight pillars. This is the starting point for the Du Family to begin their heyday. The black bricks in the bottom of the wall have been peeled off layer upon layer. The damp appearance carved with traces of weathering seems to tell of past glories and the vicissitudes of life.

The house with carved beams and painted rafters, located in the east of the principal room, is the boudoir. The boudoir is a two-storey building and is also the highest one in the Du Family courtyard, which is said to indicate the status of the daughter in the $\mathrm{Du}$ Family's mind ${ }^{[7]}$.

\section{The Tourism Development Research on Buildings of the Former Residence Category}

Since the First Ancient Village Assembly held in 2015, the heat of the topic "Protection and Activation" of the ancient villages and towns has continued rising. After starting from the water town, Wuzhen, the assembly came to Binzhou which is located at the bank of the Yellow River in Shandong Province in 2016. On the morning of October 2, 2016, the Second Ancient Village Assembly was unveiled in the International Convention and Exhibition Center in Binzhou, Shandong.

The former residence of the celebrities is regarded as a kind of important cultural heritage. Studying its development model and giving full play to its functions on the basis of creative thinking can promote the city image and the happiness index of citizens. As a product of history, the former residence has constituted the memory of a place and has reflected the spiritual culture of a place to some degree. The activation of the former residence of the celebrities helps to improve the local memory and to disseminate the local culture. In the process of activation, we should adhere to the human-oriented activation concept as well as the principle of the dynamic reality and we should activate the tourist resources of the former residence of the celebrities to add glamour to the former residence and to achieve the purpose of attracting tourists. The activation and utilization should not only reflect the cultural value of the former residence of the celebrities, but also reflect its economic value. In order to fully reflect the value of the former residence of the celebrities, we can guide the activation by using the concept of the experience economy.

The term, "Experience Economy", first appeared in a book, Future Shock, which was written by an American writer, Alvin Toffler. In 1999, Joseph Pyane and James Gilden proposed in The Experience Economy that the experience economy is another new economic form after the agricultural economy, the industrial economy and the service economy and that it takes the service as a stage and regards the commodity as a tool in order to integrate the customers into the experience economy to make them feel good and have an unforgettable experience. The experience includes four types: entertainment, education, escape and estheticism. In addition, sensory stimulation is an important part of acquiring experience.[8] The experiences of the visual sense, the auditory sense, the olfactory sense, the gustatory sense and the tactile sense are essential to visitors. Tourism is a participatory experience. To realize an all-around experience, it should not be confined to the $4 \mathrm{E}$ experience, instead, it should include the experiences of the visual sense, the auditory sense, the olfactory sense, the gustatory sense and the tactile sense. Making visitors obtain a good experience from tourism products is the basis for a pleasant experience. According to the theory of the experience economy and taking Du 
Shoutian's former residence as an example, the following strategy of activation and utilization is put forward.

\subsection{Enhancing the Entertainment Experience}

The entertainment experience is one of the oldest experiences. The visitor's experience of the former residence can be deepened through the entertainment experience. With the sun shining brightly in the morning, the black bricks and grey tiles were silently exhibited in front of me. The dense atmosphere in the air made my heart suddenly beat faster without a sign. Du Shoutian's former residence is located in the center of the ancient Phoenix Town in Binzhou. The signboard should be set up near the 205 National Highway in order to attract tourists to come here for sightseeing.

The entertainment experience projects include the celebrity life experiences, such as dressing in ancient costumes, imitating the ancients to write, using the daily life articles of the ancients and imitating the ancients to receive a guest. The unique entertainment experience is a magic weapon to attract tourists. The entertainment experience of Du Shoutian's former residence should emphasize the theme of reading, and let visitors feel the cultural ambience as well as the reading atmosphere. "A man's history of reading is the history of his spiritual development." Du Shoutian's life fully proves this viewpoint once again.

In order to enhance the tactile experience, the making materials of tourist souvenirs can be provided for the tourists, which can let the tourists participate in the souvenir making activities in person. The electronic version of "Visited this place" should be opened up and a special touch screen should be installed to keep the footprints of tourists. In addition, the tourists are encouraged to write down their travel experience. The excellent writings may be placed at the top or be encouraged through mailing souvenirs and so on.

\subsection{Enhancing the Aesthetic Experience}

Tourism is both the aesthetic process and the self-entertainment process with the purpose of gaining psychological pleasure. Its essence lies in the appreciation of the beauty as well as delight. The aesthetic experience is the main measure to promote the emotional sublimation of tourists. Du Shoutian's former residence should be activated to arouse its charm to achieve the effect of enhancing the aesthetic experience of tourists. The aesthetic experience zone can be set up in the core exhibition area of the memorial hall. Deep-level aesthetic experience can be created through deep activation ${ }^{[9]}$.

The activation of the core exhibition area of Du Shoutian's former residence should include many aspects. First, the activation of the body of the memorial hall. It includes the renovation of buildings, the rearrangement for the tablets, the restoration of the damaged historical relics, etc. In order to enhance the experience and save space, exhibition hall expand the information about itself in the form of QR codes to let the tourist scan the codes for extensive reading. Second, the activation of existing exhibits, displays as well as the venue arrangement. The lighting alteration should be carried out for the material objects as well as the exhibits and the lighting layout inside the hall should be redefined and redesigned, which can make the exhibits visible, create historical and humanistic colors and improve visual effect. The hall originally has an innovative layout of displays. The electronic color screen should be installed in an appropriate place to enrich the display modes of the former residence of the celebrities. In a lively atmosphere, the original appearance of the former residence of the celebrities can be comprehensively and effectively displayed. In addition, the voice navigation and written explanation can be set up inside the memorial hall. The background music can be added according to the exhibition environment to enhance the auditory experience of the tourist. Third, some articles in this hall can be restored according to historical materials. The material objects not collected in the hall can be modelled and displayed by computers. The tablets of the former residence can be carved on the wood and placed into a "Black Box", which can make the tourists perceive the carved rhesis through touching to enhance their experience.

\subsection{Enhancing the Escape Experience}

Tourism means that people go to somewhere else from their places of residence in order to escape from the original environment, to get rid of the annoyance and pettiness in life and to temporarily put themselves into a new environment to experience a different life. In nature, tourism has an escape function. Du Shoutian's former residence is far from the noise of the city. Stepping into this residence is like entering a retreat away from the world. Although the whole courtyard is open and smooth, the cramped and narrow living environment is still relatively cramped messy without a vast and open realm and necessary embellishment; in the big courtyard, except some ponds ahead of and behind the boudoir, there are only large and small houses and corridors of passage in the rest of the place. Unlike some southern courtyard, it shows the host's magnanimity and luxury everywhere. Flowers and plants are widely planted in Du Shoutian's former residence, which makes visitors relaxed and happy in the sense of smell. The lyre-playing, chess, calligraphy and painting matches can be held in the escape experience zone, and visitors are allowed to take part in it personally meanwhile, install some ancient orchestral instruments, and make visitors integrate into the former residence life in the sense of hearing, to make their hearts happy and feel comfortable and leisure far away from their complex life.

\subsection{Enhance Education Experience}

The edutainment is a popular education way. The purpose of Du Shoutian's former residence Tour is to express the reading theme, strengthen the educational significance of the tourism-experience, and create the similar function of "Creative Tourism", which will enrich visitors' experience during the travel, experience the education way different from the traditional classroom, participate in the experience activities, integrate with the master, be compatible with the reality, and practice what you learn. In order to enhance the education experience, some domestic and foreign celebrities may be invited to exchange their studies in the former residence to enhance their international fame. Develop the celebrity cultural works and personality quality workshop.

Contact the management department of primary and secondary schools, to make the celebrity's former residence as an extracurricular classroom for students. Develop some cultural exhibition activities and hold the reading culture festival through strengthening cooperation with the 
units. Create a characteristic reading theme tourism project and develop the corresponding educational tourism products. Set Du Family works read zone additionally, and let visitors in a particular situation for sentiment reading to enhance the education experience $^{[10]}$.

In addition, there are many interesting legends about Du Family in the folk; Du Family must have their original educational ideas and teaching methods with such glorious achievement. There are many things worth studying, while only the Du Family sentence "Learning excellence is official, not superior is not official, superior is also not official" is enough to be chewed and tasteful for a long time. Connect the legend of Du Family with the experience of education, and strengthen tourism education through the legends.

\section{Conclusion}

The prospect of the activation and utilization of tourist resources in former residences of celebrities is broad; formulate some practical strategies for activation and utilization according to its own humanistic color, historical color and geographical position in former residences of celebrities, to achieve the tourist utilization of former residence resources.

\section{References}

[1]Paul Oliver. Dwelling [M]. London: Phaidon Press, 2003: 9.

[2]DA De Vaus.Analyzing SocialScience Data, Sage Publications.

[3]M Laaziri, KJ Nath, A Gilbert. National population and housing census 1994, Victoria Seychelles Management\&Information Systems Division.

[4]A Warszawski Industrialized and Automated Building Systems, Industrialized and Automated Building
Systems.

[5] A Hashemi, K Hadjri CZemch International Conference: the

Visibility of Zero-energy Housing,

Zemch International Conference: the Visibility of Zero-energy Housing.

[6] A Hashemi, K Hadjri Offsite construction, a potential answer to the

Iranian housing shortages,

Construction Technology \&

Management $\mathrm{Ctm}$

International Scientific Conference.

[7] A Hashemi. Review of the UK Housing History in Relation to System Building, Progress in International Relations Theory.

[8] Salamati, A Asghar Urban Housing Design in Iran in Response to Socio-cultural and Environmental Conditions, University of Strathclyde.

[9] Amiri, S Yousef. A Study of the Production of Pre-fabricated Units for IndustrialBuilding Systems in Factories in Iran, University of Sheffield.[10] NO Nawari. BIM Standard in Off-Site Construction, Journal of Architectural Engineering. 